\title{
Contemporary Forms of Eugenics
}

Robert A Wilson, La Trobe University, Melbourne, Australia

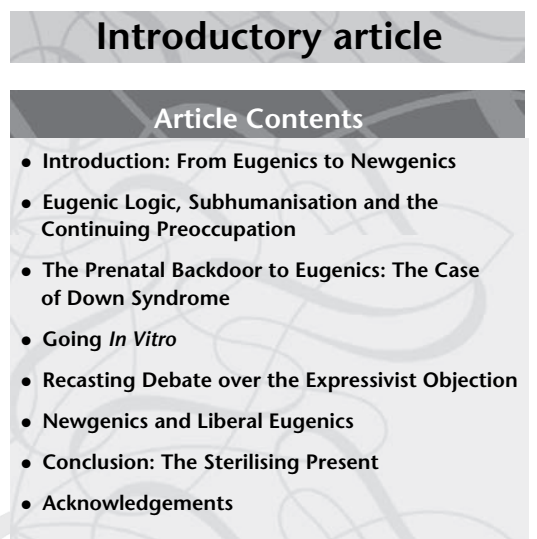

Online posting date: $15^{\text {th }}$ September 2017
Eugenics is commonly thought of as having endured as science and social movement only until 1945. With the advance of both reproductive and enhancement technologies, however, concern has arisen that eugenics has resurfaced in new forms. In particular, the eugenic potential of the Human Genome Project led to talk of the rise of 'newgenics' and of a backdoor to eugenics. This article focuses on such concerns deriving from the practice of prenatal screening and technologies that increase our ability to generate information about the kinds of children we are likely to have. Given individual preferences and social norms concerning what traits are intergenerationally desirable, how should we act and what practices and policies should we endorse or scrutinise? This article will concentrate on key components of eugenic thinking present today and emphasise continuities between the eugenic past and newgenic present in the subhumanisation of people with cognitive or intellectual disabilities.

\section{Introduction: From Eugenics to Newgenics}

The term 'eugenics' was coined by Sir Francis Galton in his 1883 book Inquiries into Human Faculty and Its Development and derives from the Greek 'eu-genes', meaning 'well-born.' There Galton defines eugenics as 'the science of improving stock-not only by judicious mating, but whatever tends to give the more

eLS subject area: Bioethics and Philosophy

How to cite:

Wilson, Robert A (September 2017) Contemporary Forms of Eugenics. In: eLS. John Wiley \& Sons, Ltd: Chichester. DOI: 10.1002/9780470015902.a0027075 suitable races or strains of blood a better chance of prevailing over the less suitable than they otherwise would have had.' Despite the fact that Galton's talk of 'stock' and 'strains of blood' require some twenty first-century updating, this quote succinctly captures three key features of eugenics: its aim, the means of achieving that aim and the relationship of eugenics to science. Galton's 'stock' is our species, Homo sapiens, and his 'strains of blood' are sorts or kinds of people. Thus, eugenics aims to use science for human improvement over generations by changing the composition of human populations through favouring the reproduction of certain sorts or kinds of people.

Historically, the science most commonly appealed to by eugenicists was genetics, and the aim of human improvement was to be achieved through government-mandated social policies, such as the sexual sterilisation of 'the feebleminded' and other sorts of people deemed undesirable. But there are many means of achieving the kind of intergenerational improvement envisioned by eugenicists through differentially intervening on actually or merely putatively distinct sorts of people. These neither need operate via state-mandated laws nor require the kind of bodily modification that sterilisation involves two often-invoked but nonessential features of eugenics prior to 1945 . Vigilante groups, such as the $\mathrm{Ku} \mathrm{Klux} \mathrm{Klan}$, that use violence to enforce practices of racial segregation in marriage, as well as immigration policies that place quotas on the immigration of certain sorts of people due to their 'inferior stock', provide historical instances of eugenic practices or policies that lack one or the other of these features.

In the early twentieth century, eugenics was conceived of both as a science and as a social movement, and it is common to think of eugenics as having endured only until 1945, ending in large part as the atrocities of the Nazis 'in the name of eugenics' became more apparent. Starting in the 1980s, and with the advance of both reproductive and enhancement technologies, however, many expressed concern that eugenics was resurfacing, taking on different forms. In particular, the eugenic potential of the Human Genome Project, the large-scale effort focused on sequencing all of the base pairs in human genome, led some to talk of eugenics as having 'gone underground', of there being a new 'backdoor to eugenics' and of the rise of 'newgenics' (Duster, 1990; Kevles and Hood, 1992). 
There have been two main and increasingly interwoven sources of concern here anchored in the trajectories taken over the last 50 years as reproductive autonomy has assumed heightened importance and technologies for modifying human beings have grown. The first relates to the practice of prenatal screening and technologies that increase our ability to generate information about the kinds of children we are likely to have. How should we act, as potential parents, in light of what traits are desirable in our children? The second appeals to the trans- or posthumanist idea of transcending the biological limitations of our embodiment, whether that be our proneness to disease or the supposed inevitability of aging and death. Here the author concentrates on the first of these, primarily due to the closer tie to the traditional eugenic concern with reproductive and intergenerational control (see sections titled 'The Prenatal Backdoor to Eugenics: The Case of Down Syndrome' to 'Recasting Debate Over the Expressivist Objection'). But first the author wants to point to some continuities between past and present forms of eugenics in the subhumanising and eliminative views of disability, particularly cognitive or intellectual disability. As we will see, views of human variation, disability and normalcy play key roles in contemporary forms of eugenics,

\section{Eugenic Logic, Subhumanisation and the Continuing Preoccupation}

The continuing preoccupation with the science of genetics, and with the control and direction of human populations through an enhanced grasp of human genetics, has been modified in light of shifts in the science of genetics itself, particularly as it has progressed beyond Mendelian genetics to incorporate population and molecular models of genetics. This progression initiated a shift among eugenicists away from the characterological study of types of people that marked early forms of eugenics towards a statistical consideration of human traits triggered by specific genetic markers (e.g. Osborn, 1940). Such a focus on statistical traits at the level of populations recognises the genetic diversity within groups and thus purportedly steers clear of the racist, classist and ableist typology of early eugenics.

At the same time, molecular genetics locates desirable and undesirable human traits at the level of deoxyribonucleic acid (DNA) sequences. As the one-time director of the Human Genome Project, James Watson, stated that project emboldened the search for genetic markers of disability in the hope of 'banishing genetic disability' (Watson, 2001, p. 228). Going molecular, like focusing on statistical traits, allows for the pursuit of the general eugenic goal of improving human populations while ostensibly avoiding the categorisation of types of 'less desirable' people tracked through blood lines. When all is settled, however, the fact remains that people with disabilities, especially intellectually disabled people, are disproportionally targeted by newgenic practices. Many disability advocates, echoing the view of those with the corresponding disabilities, argue that such eugenic targeting is inherently subhumanising. Cognitive disability may no longer be a subhuman kind in the scientific and bioethics literature as feeble-mindedness was, but it remains an especially undesirable trait.

Another way of understanding the transition from eugenics to newgenics is through what Rosemarie Garland-Thomson has termed eugenic logic - the belief that 'our world would be a better place if disability could be eliminated' (Garland-Thomson, 2012, p. 339). Eugenic logic asks "why should the world we make and occupy together include disability at all?' (p. 340). Garland-Thomson argues that while eugenic logic manifests itself in a wide array of practices and discourses - from segregation to extermination and from practical health programs to social justice initiatives - at its core it is necessarily eliminativist. That is, no matter the means of execution, disability both can and should be rooted out of populations to produce a better world. The utopian edge to eugenic logic follows from the rendering of disability as an inevitable suffering and a tragic mutation of the human condition. Disability in this reading is subhumanising, alienating us through pain, stigma, suffering, dependency and limitations from our status as proper humans. One can see the eliminativism in eugenic logic at play in contemporary practices of prenatal screening and Down syndrome.

\section{The Prenatal Backdoor to Eugenics: The Case of Down Syndrome}

In many Western countries, prenatal screening for genetic abnormalities, such as Trisomy 21, and somatic or bodily abnormalities, such as spina bifida, has been regularly encouraged as a part of prenatal care within the medical and health professions for over thirty years and is now a routine part of family planning and individual reproductive choice (Skotko, 2009). The combination of prenatal screening followed by selective abortion of a foetus found to have genetic or somatic abnormalities has become a kind of paradigm case of newgenics. As the disability studies scholar Marsha Saxton, a person who has spina bifida, says, 'The message at the heart of widespread selective abortion on the basis of prenatal diagnosis is the greatest insult: some of us are too flawed in our very DNA to exist; we are unworthy of being born.' (Saxton, 2000, p. 391). Saxton's view here is typically taken to state 'the expressivist objection' to selective abortion, and the author will return to discuss that view in section titled 'Recasting Debate Over the Expressivist Objection' after providing more background to the practice, particularly as it operates in its best-known case, that of Down syndrome.

Down syndrome is a nonhereditary, genetically based condition that is associated with male sterility, and with reduced fertility in females. Down syndrome is the most common cause of intellectual disability, accounting for approximately $20 \%$ of all known instances. It is also known as Trisomy 21 after the genetic condition that has been used through prenatal testing and screening to identify individuals with the syndrome: an extra copy of at least part of the 21st chromosome that is present in about $95 \%$ cases of Down syndrome. Children born with Down syndrome typically have mild-to-moderate intellectual disability, distinctive facial features and face a higher risk of congenital heart defects and several other susceptibilities, such as to thyroid dysfunction 
and infection due to a compromised immune system. As with other children with trisomies, their life expectancy has increased dramatically over the course of the twentieth century due to both medical advances, such as antibiotics and open-heart surgery, and societal changes, with life expectancy shifting from 9 to 11 years in the first quarter of that century to 60 years currently. Quality of life measurements likewise show reported levels that approximate those of the general population, departing from earlier assessments of this aspect of well-being (Brown et al., 2001; Gothard, 2011; Bérubé, 2014).

The incidence of Down syndrome is approximately 1 in 800 births but is unevenly distributed demographically. The best-known demographic pattern - the relationship between Down syndrome and maternal age - has been known for long enough for it to be one of the best-known cases of a foetal condition for which there is age-related screening and testing (e.g. amniocentesis). Although there is variation in the precise numbers that researchers have found, the following figures are representative of termination rates following the prenatal detection of Trisomy 21: of all the Down syndrome cases detected prenatally, $88 \%$ of those in Europe and around $85 \%$ of those in the United States result in a termination of pregnancy (Boyd et al., 2008; Natoli et al., 2013).

Despite the high incidence of Trisomy 21 in foetuses carried by pregnant women over 35 , the majority of children born with Down syndrome have mothers who are younger than 35 , since the incidence of pregnancy itself is significantly higher in that younger group. Put differently, although the incidence of Trisomy 21 rises with maternal age, the incidence of pregnancy falls with maternal age sufficiently that prenatal screening practices that focus on older mothers do not detect the majority of foetuses that have Trisomy 21.

In 2007, the Society of Obstetricians and Gynaecologists of Canada issued a clinical practice guideline that recommended that the existing reliance on maternal age as a minimum standard for prenatal screening was inadequate and should be removed as an indication for more invasive testing, such as amniocentesis, which carries with it a direct risk to the foetus (SOGD, 2007, 2012). In place of this reliance on maternal age, the guideline's principal recommended outcome is to 'offer non-invasive screening for Down syndrome or trisomy 18 to all pregnant women' (SOGD, 2007, p. 146); that recommendation is retained in the 2011 and 2012 updates to this guideline. While such practice guidelines are not binding, either legally or morally, in terms of screening practices in Canada, it both reflects and influences those practices. For all the attention to detail in the practice guideline, most striking are two points of inattention.

The first point is that nowhere in this practice guideline is any space devoted to describing what Down syndrome is like. By this the author of this present article means not only a characterisation of what it is like for an individual or a family to 'live with Down syndrome', but also even a description of the medical symptoms of, or variation in the symptoms of, those individuals with Down syndrome. The absence of such details conveys, at least implicitly, the view that the only thing that at least obstetricians and gynaecologists need to know about infants, children and adults who have been diagnosed as having Down syndrome is that they are infants, children and adults with Down syndrome. What they already share as common knowledge with members of the general public is that a diagnosis of Down syndrome is serious enough to warrant testing for its presence prenatally with an expectation of termination.

The second point is that despite the explicit emphasis on the goal of reducing the number of 'normal pregnancies lost', the most obvious effect of the recommendations remains implicit: to reduce the number of babies born with Down syndrome, and thus the number of infants, children and adults who 'live with Down syndrome'. Together with the first point, this provides a basis for viewing the combined practice of prenatal screening for Trisomy 21 together with the expectation of termination should the screen detect a foetus with Trisomy 21 as what the well-known, former U.S. Surgeon General C. Everett Koop and the conservative political commentator George Will popularised as 'search and destroy' missions, exemplifying a kind of eliminative attitude towards Down syndrome as making for life not worthy of life (Weinraub, 1981; Koop and Schaeffer, 1979; Will, 2007).

\section{Going In Vitro}

Technologies such as preimplantation genetic diagnosis (PGD) and in vitro fertilisation (IVF) are capable of screening for disability while avoiding the more pointed moral quandaries of selective abortion. PGD is already being used to profile embryos with Down syndrome and 'neural tube defects', such as spina bifida $a_{k}$ a

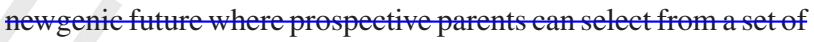
embryos the most desirable (or 'enhaneed') before implantation is not that far away.

The bioethicist and philosopher Robert Sparrow has argued that an even more extensive and deliberate form of newgenics, which he terms 'in vitro eugenics,' lurks on the biomedical horizon (Sparrow, 2014). Scientists hypothesise that in the not-too-distant future it will be possible to create human gametes from human stem cells. Sparrow argues that this technology will enable the in vitro production of multiple generations by repeatedly deriving and then combining gametes from two sources: the stem cells of the newly formed embryo and different stem-cell lines. Proceeding through multiple generations of embryos in the laboratory before implantation holds the possibility of producing desired genotypes and deliberately raising the quality of 'human stock' without the messy business of either nonconsensual sterilisation or selective abortions. Moreover, unlike PGD, and as Sparrow points out, in vitro eugenics is not limited by the chance recombination of genes, but is a deliberate selection process. The recent development of CRISPR technology (Doudna and Charpentier, 2014), which allows for germline modification of the genome in vitro, exacerbates the eugenic potential of reproductive technologies here.

\section{Recasting Debate over the Expressivist Objection}

The expressivist objection to prenatal screening followed by selective abortion arose in the 1980s as a central part of the disability rights critique of prenatal testing and selective abortion 
through the work of disability studies scholars, such as Adrienne Asch and Marsha Saxton. Asch and Saxton, amongst others, took the widespread and growing practice of selective abortion targeting foetuses with indications of later-life impairments to express a subhumanising and damaging view of people with those impairments and disabilities. Since the objection was specifically to the practice of selective abortion and many of the most prominent advocates of the objection were in general supportive of reproductive autonomy, the development of the expressivist objection did not presuppose that the foetus had a right to life and reflected, rather one point at which reproductive and disability rights clashed (Parens and Asch, 1999; Saxton, 1984, 1997, 1999; Asch, 1989, 2000, 2003; Asch and Wasserman, 2005).

One way to represent the objection is as an explicit argument that begins with the following three premises: the first making a claim about the chief function of prenatal testing, the second specifying the expectations embedded in that practice and the third drawing out one implication:

1. The practice of prenatal testing functions chiefly to detect foetuses that have a biological profile predictive of postnatal impairment.

2. The expectation (but not requirement) in individual instances of this practice is that a foetus with such a profile will be terminated, rather than carried to term.

3. Terminating a foetus primarily on the basis of its possessing a biological profile predictive of postnatal impairment implies the judgement that such a foetus is not worth carrying to term to become, in turn, a baby, infant, child and then adult with that impairment.

The word 'expressivism' comes from two conclusions drawn from these premises, one concerning what the practice itself implies and the other concerning those who participate in the practice. To articulate these conclusions in some of their strongest versions, which reflect Saxton's articulation of the objection given in section titled 'The Prenatal Backdoor to Eugenics: The Case of Down Syndrome', consider (4) and (5) below:

4. Thus, the practice of prenatal testing so applied, and with that expectation, expresses the view that people with those postnatal impairments are not worthy of life.

5. Therefore, those who participate in that practice also express the view that people with those postnatal impairments are not worthy of life.

The natural and standard reply to such strong forms of the expressivist objection is to challenge either or both inferences to these conclusions. This has been done typically by identifying other practices (such as taking folic acid) that aim to prevent the birth of a child with an impairment (such as a spina bifida), but that are not taken to express either of these extremely negative views of people with those impairments. Acting to prevent the birth of a child with spina bifida by taking folic acid during pregnancy does not imply that people with spina bifida are not worthy of life. More generally, collective practices or individual actions that aim to prevent an undesirable outcome for a specific kind of individual need not express this strongly negative view of those individuals. This is true even when those practices and actions prevent such outcomes by changing the traits of those individuals that make them of that kind.

The subhumanising connection between the practice of selective abortion on the basis of particular impairments and negative views of people with those impairments that the expressivist objection attempts to make can be preserved, however, in weaker expressions of (4) and (5) that still appeal to the eliminativist thinking at the heart of eugenic logic. Consider increasingly weakened forms of the negative attitude that (4) and (5) articulate, using just (4) illustratively:

4. Thus, the practice of prenatal testing so applied, and with that expectation, expresses the view that

(a) people with those postnatal impairments are not worthy of life.

(b) people with those postnatal impairments have a trait so negatively valued that its presence provides a sufficient reason to abort an otherwise desired pregnancy.

(c) it would be better for people to exist without those postnatal impairments.

(d) it would be better for those postnatal impairments not to exist.

(e) those later impairments are strongly negative traits of the people who have them.

While the weakening from (4a) to (4b) shifts from talking of the life worthiness of people to the negative valence of the traits they have, it preserves the connection between selective abortion and negative, subhumanising views of people with the corresponding traits by indicating the extent of the devaluation of those traits in eliminativist terms. It is not simply that traits such as having spina bifida are not regarded as neutral - as indicated by the unproblematic nature of the preventative practice of taking folic acid - but that they are sufficiently negatively valued to be difference-makers in decisions about pregnancy and termination.

If we understand such a specification of the strength of the negative evaluation of such traits to be implicit in the further weakened conclusion (4c) to (4d), we can see a kind of eliminativist logic surviving in more modest versions of the expressivist objection. This eliminativism marks a difference between preventative practices regarded as relatively morally unproblematic and the more contentious practice of selective abortion. While both reflect the view that it is better to be able-bodied than to be disabled - better to be disability-free than disability burdened - only the practice of deselection expresses the severity of the negative attitude about impairment and disability through its eliminativism. And that eliminativism provides a strong reason to view the practice of selective abortion as eugenics by other means, as eugenics underground.

\section{Newgenics and Liberal Eugenics}

One curious feature of the philosophical and bioethical literature on eugenics in the wake of concerns about the possibility of a newgenic future has been a series of defences of aspects of 
eugenics. Sometimes talking of liberal eugenics (Agar, 2004), of utopian eugenics (Kitcher, 2000) or of parental obligations in light of the technologically enhanced possibilities for the 'eugenic selection of embryos' (Savulescu, 2001), philosophers have attempted to sort the wheat from the chaff of eugenic intervention in the contemporary biotechnological landscape. While such views reflect recognition of the reality of the value that is placed on individual reproductive autonomy in contemporary society, less often noted is that they also share an assumption about the negative value that disability has in the context of individual choices here.

Agar, for example, thinks of human improvement as a kind of by-product of technology that 'is mainly used to avoid passing on genetic variants linked with serious diseases', Here $\overline{\mathbf{2}}_{\mathbf{2}}$ Agar assumes an antithetical relationship between having any such variant and the meliorative project of human improvement. The sweep of this generalisation should serve as a flag for those wary of the translation of the negative valuation of a trait into eliminativist practices. While the eradication of some such diseases, such as Tay-Sachs and other early-onset, short-life inducing diseases and conditions, unquestionably contribute to that meliorative project, the overwhelming majority of 'genetic variants linked to serious diseases' stand in a more complicated and problematic relationship to the goal of human improvement. In part, this is because the linkages between genetic variation and serious disease are pervasive, often probabilistic and mediated by genetic, somatic and external environmental factors. But it is also because even 'serious diseases' with clear, localised and decisive genetic causes themselves range from the extreme case of Tay-Sachs, where eradication seems relatively uncontroversial, to those that are compatible with lives that are, until mid- to late-life onset, healthy and fulfilling, Huntington's disease being one well-known example. Hereditary blindness, deafness and epilepsy - to take eugenic traits that would typically be regarded as serious, hereditarily transmissible diseases and that featured in the central Nazi sterilisation law from 1933 - are three further examples that should give pause to whether Agar's 'individual eugenic choices' will improve human stock in ways that are more acceptable than state-mandated eugenics. Given the pervasive ableism in our society, individual decision-makers under the influence of eugenic logic will likely make choices that equate disability with suffering, pity and something to be avoided or eliminated at even relatively high cost.

\section{Conclusion: The Sterilising Present}

We have seen the debate over contemporary forms of eugenics focuses on technologies of reproduction and human enhancement and have implicitly accepted the view that 'old eugenics' is very much a matter of the past. Yet a number of cases in recent years call that view into question, adding another dimension to the contemporary forms that eugenics takes. All of these cases involve the sterilisation of just the sorts of people who were explicitly targeted in past sexual sterilisation laws.

In 2012, Australia's Senate launched an inquiry into the ongoing, often nonconsensual sterilisation of girls and women with disabilities, a practice that had been brought to light through Medicare billing records. Unlike Canada and the United States, Australia had never passed sexual sterilisation legislation, but the affinity between what was happening then and there in Australia and the broader eugenic past was part of what garnered the attention of the Senate. Floating free of explicit state-sanctioned policy, the documented practice of sterilising women and girls with disabilities 'for their own good' nonetheless often rested on eugenic arguments and sat uneasily with Australia's formal human rights commitments, as argued in a detailed submission to the Senate Inquiry by the advocacy group Women With Disabilities Australia (2013).

During the summer of 2013, Cory Johnson of the Center for Investigative Reporting reported that between 2006 and 2010 about one hundred and fifty Latina and African-American women in the California prison system had been recently sterilised under conditions of dubious consent or where consent was missing altogether (Johnson, 2013). The matter was put before the California legislature for discussion. As the state where more sterilisations had been carried out than in any other American jurisdiction in the heyday of eugenics - about one-third of the then-legal eugenic sterilisations performed in the United States between 1907 and 1977 had occurred in California - legislators in the state were very much aware of the need to acknowledge the legacy of a eugenic past, as evidenced by Governor Gray Davis's formal apology for California's eugenic history and California's Senate Resolution No. 20, passed in 2003, expressing 'profound regret' over the state's involvement in eugenics. In the wake of the 2013 report of ongoing sterilisations, what seemed needed was not so much an acknowledgement of a eugenic past as more immediate steps to halt a continuing eugenic present.

At the end of 2014, more than a dozen women in the central Indian state of Chhattisgarh died after undergoing sexual sterilisation as part of a paid incentive program that was aimed in part to control poverty (The Guardian, 2014; CNN, 2014; BBC, 2014). They died of blood poisoning or haemorrhagic shock following their sterilisation, and the news story became widespread because few outside of India, and perhaps within it, knew of the extensiveness and routine nature of this sterilisation program. According to United Nations statistics compiled in 2006 , as many as $37 \%$ of Indian women have undergone sexual sterilisation, many as part of this incentive program, which offers free sterilisation for women and pays them $\$ 10-20$, amounting to more than a week's salary for many of them.

\section{Acknowledgements}

This article reworks some material from a paper coauthored with Joshua St. Pierre, 'Eugenics and Disability' that appeared in Patrick Devlieger, Beatriz Miranda-Galarza, Steven E. Brown and Megan Strickfaden, eds, Rethinking Disability: World Perspectives in Culture and Society (Antwerp: Garant Publishing, 2016), 93-112, that is also developed further in chapter 7 of my The Eugenic Mind Project (Cambridge, MA: MIT Press, 2017). I thank Josh for permission to rework the material here. 


\section{References}

Agar N (2004) Liberal Eugenics: In Defence of Human Enhancement. Cambridge: Blackwell.

Asch A (1989) Reproductive technology and disability. In: Cohen S and Taub N (eds) Reproductive Laws for the 1990s, pp. 69-124. Clifton, NJ: Humana Press.

Asch A (2003) Disability equality and prenatal testing: contradictory or compatible? Florida State University Law Review 30: 315-342.

Asch A (2000) Why I haven't changed my mind about prenatal diagnosis: reflections and refinements. In: Parens E and Asch A (eds) Prenatal Testing and Disability Rights, pp. 234-258. Washington, DC: Georgetown University Press.

Asch A and Wasserman D (2005) Where is the sin in synecdoche?: prenatal testing and the parent-child relationship. In: Wasserman $\mathrm{D}$, Bickenbach J and Wachbroit R (eds) Quality of Life and Human Difference: Genetic Testing, Health Care, and Disability, pp. 172-216. New York: Cambridge University Press.

BBC (2014) India's Dark History of Sterilisation, (by Soutik Biswas). http://www.bbc.com/news/world-asia-india-30040790.

Bérubé M(2014) Down Syndrome. EugenicsArchive.ca. Retrieved May 7, 2017. http://www.eugenicsarchive.ca/discover/ encyclopedia/535eeb507095aa000000021d

Boyd P, DeVigan C, Khoshnood B, et al. (2008) Survey of prenatal screening policies in Europe for structural malformations and chromosome anomalies, and their impact on detection and termination rates for neural tube defects and Down's syndrome. BJOG: An International Journal of Obstetrics and Gynaecology 115: 689-696.

Brown R, Taylor J and Matthews B (2001) Quality of life_ageing and Down syndrome. Down Syndrome Research and Practice 6 (3): 111-116.

CNN (2014) India Sterilization Program Under Fire After Women's Deaths (by Greg Botelho, SugamPokharelandSumnimaUdas). http://www.cnn.com/2014/11/12/world/asia/india-sterilizationdeaths/.

Doudna JA and Charpentier E (2014) The new frontier of genome engineering with CRISPR-Cas9. Science 346 (6213): 1258096.

Galton F (1883) Inquiries into Human Faculty and its Development. London: MacMillan.

Garland-Thomson R (2012) The case for conserving disability. Journal of Bioethical Inquiry 9 (3): 339-355.

Gothard J (2011) Greater Expectations: Living with Down Syndrome in the $21^{s t}$ Century. Fremantle: Fremantle Press.

Johnson C(2013) Female Inmates Sterilized in California Prisons without Approval, Center for Investigative Reporting. http://cironline.org/reports/female-inmates-sterilized-californiaprisons-without-approval-4917

Kitcher P (2000) Utopian eugenics and social inequality. In: Sloan PR (ed) Controlling Our Destinies: Historical, Philosophical, Ethical, and Theological Perspectives on the Human Genome Project, pp. 229-262. Notre Dame, IN: University of Notre Dame Press. Reprinted in Kitcher's In Mendel's Mirror: Philosophical Reflections on Biology. New York: Oxford University Press, 2003..

Koop CE and Schaeffer FA (1979) Whatever Happened to the Human Race? Westchester, IL: Crossway Books.

Natoli JL, Ackerman DL, McDermott S and Edwards JG (2013) Prenatal diagnosis of Down syndrome: a systematic review of termination rates (1995-2011). Prenatal Diagnosis 32 (2): 142-153.
Osborn F (1940) Preface to Eugenics. New York: Harper and Brothers.

Parens, E and Asch A (1999) Disability Rights Critique of Prenatal Genetic Testing: Reflections and Recommendations. Hastings Center Report Sept-Oct 1999, S1-22. Reprinted in Parens E and Asch A (eds) Prenatal Testing and Disability Rights Washington, DC: Georgetown University Press, 2000, pp. 3-43.

Savulescu J (2001) Procreative beneficence: why we should select the best children. Bioethics 15 (5/6): 413-426.

Saxton M (1984) Born and unborn: the implications of reproductive technologies for people with disabilities. In: Arditti R, Duelli Klein R and Minden S (eds) Test-Tube Women: What Future for Motherhood, pp. 298-312. London: Pandora Press.

Saxton M (1997) Disability rights and selective abortion. In: Solinger R (ed) Abortion Wars: A Half Century of Struggle, 1950-2000, pp. 374-395. Berkeley, CA: University of California Press.

Saxton M (2000) Why members of the disability community oppose prenatal diagnosis and selective abortion. In: Parens E and Asch A (eds) Prenatal Testing and Disability Rights, pp. 147-164. Washington, DC: Georgetown University Press.

Skotko BG (2009) With new prenatal testing, will babies with Down syndrome slowly disappear? Archives of Disease in Childhood $\mathbf{9 4}$ : 823-826.

SOGD (2007) Prenatal screening for fetal aneuploidy. Journal of Obstetricians and Gynaecologists of Canada 187: 146-161.

SOGD (2012) Counselling considerations for prenatal genetic screening. Journal of Obstetricians and Gynaecologists of Canada 277: 489-493.

Sparrow R (2014) In vitro eugenics. Journal of Medical Ethics 40 (11): 725-731.

The Guardian (2014). Indian Mass Sterilisation: Women Were 'Forced' into Camps, Say Relatives (by Jason Burke). https://www.theguardian.com/world/2014/nov/12/indiasterilisation-deaths-women-forced-camps-relatives

Watson J (2001) A Passion for DNA: Genes, Genomes, and Society. Cold Spring Harbor: Cold Spring Harbor Laboratory Press.

Weinraub B (1981) Reagan Nominee for Surgeon General Runs into Obstacles on Capitol Hill. New York Times, 7 April 1981, p. A16/6.

Will GF (2007) Golly, What Did Jon Do? Newsweek (29 January 2007).

Women With Disabilities Australia (2013) Dehumanised: The Forced Sterilisation of Women and Girls with Disabilities in Australia. WWDA Submission to the Senate Inquiry into the Involuntary or Coerced Sterilisation of People with Disabilities in Australia (March 2013). http://wwda.org.au/papers/subs/subs2011/.

\section{Further Reading}

Amundson R (2005) Disability, ideology, and quality of life. In: Wasserman D, Bickenbach J and Wachbroit R (eds) Quality of Life and Human Difference: Genetic Testing, Health Care, and Disability, pp. 101-120. Cambridge: Cambridge University Press. Cowan RS (2008) Heredity and Hope: The Case for Genetic Screening. Cambridge, MA: Harvard University Press.

Goering S (2014) Eugenics. In: Zalta EN (ed) The Stanford Encyclopedia of Philosophy, Fall 2014 edn.

Kevles D and Hood L (eds) (1992) The Code of Codes: Scientific and Social Issues in the Human Genome Project. Cambridge, MA: Harvard University Press. 
EugenicsArchive (2014) Living Archives on Eugenics in Western Canada. www.eugenicsarchive.ca

Marks J (1993) Historiography of eugenics. American Journal of Human Genetics 52 (3): 650-653.

Miller J, Fairbrother N and Wilson RA (2015) Surviving Eugenics. Vancouver, BC: Moving Images Distribution.

Silvers A (2016) Disability and normality. In: Solomon M, Simon JR and Kincaid H (eds) Routledge Companion to Philosophy of Medicine, pp. 36-47. New York: Routledge.
Taylor S (2017) Beasts of Burden: Animal and Disability Liberation. New York: The New Press.

Wilson RA (in press) The Eugenic Mind Project. Cambridge, MA: MIT Press. 
Article Title: Contemporary Forms of Eugenics

Article ID: a0027075

Article DOI: 10.1002/9780470015902.a0027075

Article copyright holder: John Wiley \& Sons, Ltd.

Version: 1

Previous version(s): $* * * *$

Article Type: Standard

Readership Level: Introductory article

Top level subject categories: Bioethics and Philosophy

Keywords: disability \# Down syndrome \# eugenics \# newgenics \# prenatal screening \# reproductive technologies \# sterilisation \# subhumanisation

\section{Key Concepts}

- Disability is often conceptualised in biomedical terms as a kind of subnormal functioning, a conception challenged within the disability community in part for how it underplays the importance of social dimensions to disability.
- Down syndrome names the human chromosomal variation most routinely screened and tested for through the use of reproductive technologies.

- Eugenics is a set of ideas and practices aimed at improving the human species by differentially selecting for or against certain sorts of people to populate future generations.

- Newgenics is shorthand for 'new forms of eugenics'.

- Prenatal testing includes a range of reproductive technologies that inform one about the likely features that offspring will have.

- Reproductive technologies can both facilitate and limit choices in reproduction and include prenatal screening and testing, in vitro fertilisation (IVF), and preimplantation genetic diagnosis (PGD).

- Sterilisation is a reproductive technology that halts reproduction that can be voluntarily and temporarily undertaken but whose best-known instances relating to eugenics were compulsory and permanent.

- Subhumanisation is both the process of treating someone as less than fully human and the outcome of that process, and is perhaps more often referred to as 'dehumanisation'.

Author(s) and Affiliation(s):

Robert A Wilson, La Trobe University, Melbourne, Australia 


\section{Author Query Form}

Title: eLS

Entry Title/Article No: Contemporary Forms of Eugenics/a0027075

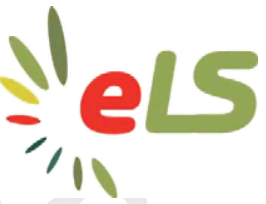

Dear Author,

During the preparation of your manuscript for typesetting some questions have arisen. These are listed below. Please check your typeset proof carefully and mark any corrections in the margin of the proof or compile them as a separate list.

\section{Queries and/or remarks}

\begin{tabular}{|c|c|}
\hline AU:1 & $\begin{array}{l}\text { As per style, glossary is mandatory; keywords will be used to generate the glossary. Please supply definitions for the } \\
\text { keywords for this article. Please keep the definitions short, clear, and precise; preferably upto } 10 \text { words. }\end{array}$ \\
\hline AU:2 & $\begin{array}{l}\text { We notice that there are no cross-references to other eLS articles in this article. Cross-references add considerable } \\
\text { value to an online reference such as eLS. Please refer to your proofreading instructions if you would like to add } \\
\text { cross-references to published eLS articles. }\end{array}$ \\
\hline AU:3 & $\begin{array}{l}\text { References "Duster, 1990, Saxton, 1999" are cited in text but not provided in the list. Please provide references in list } \\
\text { or delete the citations. }\end{array}$ \\
\hline AU:4 & The citation "Kevles, 1995" (original) has been changed to "Kevles and Hood, 1992". Please check if appropriate. \\
\hline AU:5 & $\begin{array}{l}\text { The citation "Garland-Thompson, 2012" (original) has been changed to "Garland-Thomson, 2012". Please check if } \\
\text { appropriate. }\end{array}$ \\
\hline AU:6 & The citation “Boyd et al., 2009" (original) has been changed to "Boyd et al., 2008”. Please check if appropriate. \\
\hline AU:7 & The citation "Asch, 1999" (original) has been changed to "Asch, 2000". Please check if appropriate. \\
\hline AU:8 & $\begin{array}{l}\text { Pleae provide valid urls for "http://cironline.org/reports/female-inmates-sterilized-california-prisons-without-approval- } \\
\text { 4917", " https://www.theguardian.com/world/2014/nov/12/india-sterilisation-deaths-women-forced-camps-relatives", } \\
\text { "http://www.bbc.com/news/world-asia-india-30040790". }\end{array}$ \\
\hline AU:9 & Please provide publication year for Reference "Wilson (in press)". \\
\hline
\end{tabular}

